\title{
The Handwritting Margins Pattern Recognition To IDentify Human Character Using Support Vector Machine Method
}

\author{
Ratnadewi ${ }^{1)}$, Adiatandy Geovani ${ }^{2}$ \\ 1) Maranatha Christian University, Bandung, Indonesia \\ E-mail: ratnadewi.bandung@gmail.com \\ 2) Maranatha Christian University, Bandung, Indonesia
}

\begin{abstract}
The study of a person's character by handwriting analysis called graphology. Handwriting analysis is using in many areas, for example in education, crime and forensic. In graphology there are some aspects that are used to determine a person's character, such as by analyzing: margin or fringe spacing writing, spacing or distance between words or lines of text, baseline of writing, font size, the pressure of writing, writing zone, the slope of the writings, literary type, writing speed, and unique letter.

In this paper, we are designed a system using support vector machine (SVM) algorithm to recognize patterns of margins paper of human handwriting, by find out the minimum value for left margin and maximum value for right margin of in entire image that will become input from the training data and testing data in support vector machine (SVM) algorithm.

Handwriting margin paper pattern recognition on this paper successfully realized. In training, the result has $92 \%$ recognize well with 42 training data for left and for test case, the result has $90 \%$ recognize with 10 testing data for left, and then the result has $71.4 \%$ recognize well with 42 training data for right and in test case, this software has $70 \%$ recognize with 10 testing data for right.
\end{abstract}

Keywords: Handwriting Margin Pattern Recognition. 